\title{
Applying of F2 (0.004) forecasting the number of tourists in Sanya
}

\author{
${ }^{a}$ Xue-Bin Huang, ${ }^{b,}{ }^{*}$ Hong-Xu Wang, ${ }^{c}$ Zhen Chen and ${ }^{\mathrm{d}}$ Xi Zhang \\ Hainan Tropical Ocean University, China - Austria College, Hainan, Sanya, China, \\ 572022 \\ Email: ${ }^{a}$ pku.huang@qq.com, ${ }^{b}$ whx16233@126.com, ${ }^{c}$ chenresearch@163.com, \\ d727093568@qq.com \\ *Corresponding author
}

\begin{abstract}
The prediction formula of F2 (0.004) relies on inverse fuzzy numbers, the difference of historical data and the differential-difference of the historical data. F2 (0.004) is a fuzzy time-series forecasting model. This paper reports the application of F2 (0.004) on forecasting research about the historical data of tourist number in Sanya from 2006 to 2014 and the number of tourists in the unknown year 2015. For the study of time series forecasting problems, F2 (0.004) is an added new methods.
\end{abstract}

Keywords: Fuzzy Time Series Forecasting Model; F2 (0.004); Inverse Fuzzy Numbers; Differential-Difference; The number of Tourists.

\section{Introduction}

It has added a new powerful tool on uncertainty problem research, since Zahde[1] funded the fuzzy set theory. Regarding the time series as fuzzy systems, Song Et al[2-4] brought up the first fuzzy time series forecasting model in 1993 for studying the prediction problem of the registered number in Alabama University from 1971 to 1992 (referred to as the classic case). Later, people constantly put forward various improved forecasting models. In 2012, Saxena et al[5] proposed a new fuzzy time-series forecasting model based on inverse fuzzy numbers, making the average forecast error rate reach an unprecedented prediction accuracy: for the classic cases, the average forecast error rate: $\mathrm{AFER}=0.3406 \%$ and the mean square error: $\mathrm{MSE}=9169$. Wang et al[6-10] made further improvements for the inverse fuzzy forecasting model, not only greatly simplifying the calculation processes, but improving the prediction accuracy when applied to the classic case. For example, Wang et al[10] proposed a method to obtain AFER $=0.1705 \%$ and MSE $=1121$. In this article, the forecasting model in the literature [10] is modified, called F2 (0.004). It 
makes the prediction formula more streamlined. F2 (0.004) is an element of the collection of forecasting model FTSFM 2 (Fuzzy Time Series Forecasting Model 2). F2 (0.004) is a better fuzzy time-series forecasting model. This model can be utilized to study the predicted values of the historical data about the number of tourists in Sanya from 2006 to 2014 and the predicted values in the unknown year 2015. Therefore, it is worth being recommended.

\section{Collection of forecast model FTSFM 2}

Forecasting Formula:

$\xi_{i}=\frac{\mu+1}{\frac{\mu}{V_{i-1}}+\frac{1}{S_{i}}}, T_{i}=U_{i-1}+\xi_{i}+V_{i-1}, \mu \in(0,1)$,

Where: $\xi_{\mathrm{i}}$ is the inverse fuzzy numbers of the year $\mathrm{i}, \mathrm{V}_{\mathrm{i}}$ is the difference of historical data of the year $\mathrm{i}-1, \mathrm{~S}_{\mathrm{i}}$ is the differential-difference of the historical data of the year $i, T_{i}$ is the predicted values of the historical data of the year $i$, $\mathrm{U}_{\mathrm{i}-1}$ is the historical data of the year $\mathrm{i}-1, \mu \in(0,1)$ is called $\left(\mathrm{V}_{\mathrm{i}}\right.$ 's) Membership Degree.

When determining $\mu \in(0,1)$, resulting a formula (1) as the prediction formula of the forecasting model, recording it as F2 $(\mu)$. The collection of all the forecasting model F2 $(\mu),(\mu \in(0,1)$, ) was recorded as FTSFM 2.

Definition 1: If when forecasting the registered number of Alabama University from 1971 to 1992 , resulting that AFER $\leq 0.3406 \%$ and MSE $\leq$ 9169 , then the fuzzy time-series forecasting model is known as a better fuzzy time-series forecasting model.

It can prove that the commonly used forecasting model F2 (0.004) is a better fuzzy time-series forecasting model.

\section{Application process of $\mathrm{F} 2(\mathbf{0 . 0 0 4})$}

Step1: Entering historical data; Step 2: Building 3 discourse domains of historical data; Step 3: Building F2 (0.004) prediction formula; Step 4: Applying the F2 (0.004) to predict historical data; Step 5: Applying the F2 (0.004) to predict data of unknown years.

\section{Application of F2 (0.004) to study the prediction problem on tourist number in Sangya}

The whole application process was showed through the case where using the F2 (0.004) to research the prediction problem which related to the number of the 
tourist in Sanya between 2006 and 2014.

\subsection{Entering the historical data}

Entering the historical data of tourist arrivals in Sanya from 2006 to 2014 and showing in Tab. 1.

Tab. 1 Applying of the F2(0.004) Forecasting the Tourist Arrivals in Sanya from 2006 to 2014

\begin{tabular}{|c|c|c|c|c|c|c|}
\hline years & $\begin{array}{c}\text { Tourist } \\
\text { number } \\
\mathrm{U}_{\mathrm{i}} \\
(10 \mathrm{k})\end{array}$ & $\begin{array}{c}\text { Differenc } \\
\text { e of } \\
\text { tourism } \\
\text { number } \\
\mathrm{V}_{\mathrm{i}}\end{array}$ & $\begin{array}{c}\text { Different } \\
\text { ial-differ } \\
\text { ence } \\
\mathrm{S}_{\mathrm{i}}\end{array}$ & $\begin{array}{c}\text { Predicted } \\
\text { values of } \\
\text { tourist } \\
\text { number } \\
\mathrm{T}_{\mathrm{i}}(10 \mathrm{k})\end{array}$ & $\left(T_{i}-U_{i}\right)^{2}$ & $\left|T_{i}-U_{i}\right| / U$ \\
\hline 2006 & 454.90 & & & & & \\
\hline 2007 & 538.43 & 83.53 & & & & \\
\hline 2008 & 604.15 & 65.72 & -17.81 & 604.06 & 0.0081 & 0.000149 \\
\hline 2009 & 669.05 & 64.90 & -0.82 & 669.05 & 0.0000 & 0.000000 \\
\hline 2010 & 882.65 & 213.60 & 148.70 & 881.98 & 0.4489 & 0.000759 \\
\hline 2011 & $\begin{array}{c}1021.0 \\
7\end{array}$ & 138.42 & -75.18 & 1020.66 & 0.1681 & 0.000402 \\
\hline 2012 & $\begin{array}{c}1102.2 \\
2\end{array}$ & 81.15 & -57.27 & 1101.90 & 0.1024 & 0.000290 \\
\hline 2013 & $\begin{array}{c}1228.4 \\
0 \\
\end{array}$ & 126.18 & 45.03 & 1228.48 & 0.0064 & 0.000065 \\
\hline $\begin{array}{c}201 \\
4 \\
\end{array}$ & $\begin{array}{c}1352.7 \\
6 \\
\end{array}$ & 124.36 & -1.82 & 1352.75 & 0.0001 & 0.000007 \\
\hline MSE & & & & & 0.1049 & \\
\hline $\begin{array}{c}\mathrm{AFE} \\
\mathrm{R}\end{array}$ & & & & & & $0.0239 \%$ \\
\hline
\end{tabular}

\subsection{Building 3 discourse domains}

Building discourse domains of the number of tourist in Sanya according to the Table 1: $\mathrm{U}=\left\{\mathrm{U}_{2006}=454.90, \mathrm{U}_{2007}=538.43, \ldots, \mathrm{U}_{2013}=1228.40, \mathrm{U}_{2014}=1352.76\right\}$. Using the formula $\mathrm{V}_{\mathrm{i}}=\mathrm{U}_{\mathrm{i}}-\mathrm{U}_{\mathrm{i}-1}$ to calculate and building the every-year difference domain of the tourist number in Sanya: $V=\left\{V_{2007}=83.53, V_{2008}=65.72, \ldots\right.$, $\left.\mathrm{V}_{2013}=126.18, \mathrm{~V}_{2014}=124.36\right\}$.

Using the formula $S_{i}=V_{i}-V_{i-1}$ to calculate and building the every-year differential-difference domain of the tourist number in Sanya: $S=\left\{S_{2008}=-17.81\right.$, $\left.\mathrm{S}_{2009}=-0.82, \ldots, \mathrm{S}_{2013}=45.03, \mathrm{~S}_{2014}=-1.82\right\}$. 


\subsection{Building F2 (0.004) prediction formula}

F2 (0.004) is an element of FTSFM 2 (Fuzzy Time Series Forecasting Model 2) and the F2(0.004) prediction formula was constructed on the basis of the three above-mentioned domains:

$$
\xi_{i}=\frac{0.004+1}{\frac{0.004}{V_{i-1}}+\frac{1}{S_{i}}}, T_{i}=U_{i-1}+\xi_{i}+V_{i-1}
$$

Where: $\xi_{i}$ is the inverse fuzzy numbers of the year $i, V_{i-1}$ is the difference of tourism number of the year $\mathrm{i}-1, \mathrm{~S}_{\mathrm{i}}$ is the differential-difference of the tourism number of the year $\mathrm{i}, \mathrm{T}_{\mathrm{i}}$ is the predicted values of the tourist number of the year $\mathrm{i}$, $\mathrm{U}_{\mathrm{i}-1}$ is the tourist number of the year i-1, $\mu=0.004$ is the (Vi's) Membership Degree.

It is obviously to see that the prediction formula is constructed within the framework of the inverse fuzzy numbers.

\subsection{Applying the F2 (0.004) forecasting the tourist number in Sanya between 2008 and 2014}

Applying F2 (0.004) prediction formula (2) calculated the forecasting value of the number of tourists in Sanya from 2008 to 2014 and tested it, then filled in Table 1 . It can be seen from Table 1 that the AFER $=0.0339 \%$ and the MSE $=$ 0.2221 , so the prediction accuracy is higher.

\subsection{Applying the F1 (0.004) to forecasting the tourist number in Sanya between 2014 and 2015}

It is expectant that the tourist number in 2015 can be forecasted from the perspective of the research on data. Because of the lack of the differential-difference of the tourist arrivals in $2015 \mathrm{~S}_{2015}$, the predicted value cannot be directly calculated by using the prediction formula (2). Therefore, it is needed to create F2(0.004) prediction rule on forecasting the unknown year's tourist number in order to fill the missing $\mathrm{S}_{2015}$.

\subsubsection{F1(3-4-4) prediction rule}

Set: three years before year $i$ is respectively year $i-3$, i-2 and $i-1$, and the differential-difference of each year's historical data is respectively $\mathrm{S}_{\mathrm{i}-3}, \mathrm{~S}_{\mathrm{i}-2}$ and $\mathrm{S}_{\mathrm{i}-1 .} \quad$ Calculate: $\delta=\left\{\max \left\{S_{i-1}, S_{i-2}, S_{i-3}\right\}-\min \left\{S_{i-1}, S_{i-2}, S_{i-3}\right\}\right\} / 3$, Respectively use parameters $\mathrm{V}_{\mathrm{i}-4}$ and $\mathrm{S}_{1}=\min \left\{S_{i-1}, S_{i-2}, S_{i-3}\right\} ; \mathrm{V}_{\mathrm{i}-3}$ and 
$\mathrm{S}_{2}=\min \left\{S_{i-1}, S_{i-2}, S_{i-3}\right\}+\delta ; \mathrm{V}_{\mathrm{i}-3}$ and $\mathrm{S}_{3}=\min \left\{S_{i-1}, S_{i-2}, S_{i-3}\right\}+2 \delta ; \mathrm{V}_{\mathrm{i}-2}$ and $\mathrm{S}_{4}=\max \left\{S_{i-1}, S_{i-2}, S_{i-3}\right\}$; and $\mathrm{U}_{\mathrm{i}-1}$; Apply F2 (0.004) prediction formula to calculate and the results by ascending order are the small predictive value, smaller predictive value, larger predictive value and large predictive value of the data of the unknown year i. This prediction rule is called F2(3-4-4) prediction rule.

\subsubsection{Decision method for predicted value}

The first decision method is: the recommend order of small, smaller, larger and large predictive value of the unknown year 2015 is consistent with the ascending order of the prediction error rate between the small, smaller, larger, large predictive value of the historical data in 2014 and the actual value. The second decision method is: the decision-makers select an order relied on their own experience.

\subsubsection{Applying the F2(3-4-4) to calculate the predicted value of the tourist number in unknown year}

4.5.3.1.Applying the F2(3-4-4) prediction rules to forecast the tourist number in Sanya in the unknown year 2014

Regarding year 2014 as the unknown year, applying F2(3-4-4) prediction rules forecasted the number of tourist in Sanya in the unknown year 2014. In Table 1, the every-year differential-difference of the historical data between 2011 and 2013 is respectively $S_{2011}=-75.18, S_{2012}=-57.27, S_{2013}=45.03$.

Calculate

$$
\delta=\left\{\max \left\{S_{2011}, S_{2012}, S_{2013}\right\}-\min \left\{S_{2011}, S_{2012}, S_{2013}\right\}\right\} / 3=\{45.03-(-75.18)\} / 3=40.07
$$

Respectively use parameters $\mathrm{V}_{2010}=213.60$ and $\mathrm{S}_{1}=\min \left\{S_{2011}, S_{2012}, S_{2013}\right\}=$ -75.18, $\mathrm{W}_{2011}=138.42$ and $\mathrm{S}_{2}=\min \left\{S_{2011}, S_{2012}, S_{2013}\right\}+\delta=-75.18+40.07=$ $-35.11, \mathrm{~W}_{2011}=138.42$ and $\mathrm{S}_{3}=\min \left\{S_{2011}, S_{2012}, S_{2013}\right\}+2 \delta=-75.18+80.14=$ $4.96, \mathrm{~W} \quad 2012=81.15$ and $\mathrm{S}_{4}=\max \left\{S_{2011}, S_{2012}, S_{2013}\right\}=45.03$, Take $\mathrm{U}_{2013}=1228.40$ and apply F2(0.004) prediction formula (2) to calculate.

The values obtained by ascending order are the small, smaller, larger and large predictive value of the number of tourist in the unknown year 2014. As shown in Tab. 2.

All the calculation and test results of the predicted value of Snaya in the unknown year 2014 were filled in Table 2. According to Table 2, it can be drawn that the prediction error rate between the predicted value and the actual data 
from small to large is: the first one is the smaller predictive value, the second one is the larger predictive value, the third one is the large predictive value and the last one is the small predictive value. This order is the recommend order of the predicted value in 2015 .

Tab. 2 Applying F2(3-4-4) prediction rules to forecast the tourist number in Sanya in 2014

\begin{tabular}{|l|l|l|l|l|l|}
\hline years & $\begin{array}{l}\text { Predicted } \\
\text { types }\end{array}$ & $\begin{array}{l}\text { Predicted } \\
\text { value in } \\
2014(10 \mathrm{k})\end{array}$ & $\begin{array}{l}\text { Actual value } \\
\text { in 2014 } \\
(10 \mathrm{k})\end{array}$ & $\mid T_{2014}-U_{2014} / U_{2014}$ & $\begin{array}{l}\text { Order of the } \\
\text { prediction error rate } \\
\text { comparing to the } \\
\text { actual value }\end{array}$ \\
\hline 2014 & Small & 1331.53 & 1352.76 & $1.5694 \%$ & 4 \\
2014 & $\begin{array}{l}\text { predictive } \\
\text { value }\end{array}$ & 1354.66 & 1352.76 & $0.1405 \%$ & 1 \\
& $\begin{array}{l}\text { Smaller } \\
\text { predictive } \\
\text { value } \\
\text { Larger } \\
\text { predictive } \\
\text { value } \\
\text { Large } \\
\text { predictive } \\
\text { value }\end{array}$ & 1366.41 & 1352.76 & $1.0090 \%$ & 2 \\
& & 1352.76 & $1.4075 \%$ & \\
& & & & \\
\end{tabular}

\section{Applying F2(3-4-4) prediction rules to predict the tourist number of Sanya in the unknown year 2015}

Regarding year 2015 as the actual unknown year, applying F2(3-4-4) prediction rule forecasted the number of tourist of Sanya in 2015. In Tab. 1, the every-year differential-difference of the tourist number between 2012 and 2014 is respectively $\mathrm{S}_{2012}=-57.27, \mathrm{~S}_{2013}=45.03, \mathrm{~S}_{2014}=-1.82$.

Calculate

$\delta=\left\{\max \left\{S_{2012}, S_{2013}, S_{2014}\right\}-\min \left\{S_{2012}, S_{2013}, S_{2014}\right\}\right\} / 3=\{45.03-(-57.27)\} / 3=34.10$

Respectively use parameters $\mathrm{V}_{2011}=138.42$ and $\mathrm{S}_{1}=\min \left\{S_{2012}, S_{2013}, S_{2014}\right\}=$ -57.27, $\mathrm{V}_{2012}=81.15$ and $\mathrm{S}_{2}=\min \left\{S_{2012}, S_{2013}, S_{2014}\right\}+\delta=-57.27+34.10=$ $-23.17, \mathrm{~V}_{2012}=81.15$ and $\mathrm{S}_{3}=\min \left\{S_{2012}, S_{2013}, S_{2014}\right\}+2 \delta=-57.27+68.20=$ 10.93, $\mathrm{V}_{2013}=126.18$ and $\mathrm{S}_{4}=\max \left\{S_{2012}, S_{2013}, S_{2014}\right\}=45.03$. Take $\mathrm{U}_{2014}=1352.76$ and apply $\mathrm{F} 2(0.004)$ prediction formula (2) to calculate. The values obtained by ascending order are the small, smaller, larger and large predictive value of the number of tourist in the unknown year 2015. As shown in Tab. 3. 
According to the first decision method, the recommend orders can be drawn in the Table 2. The first one is the smaller predictive value at 1433.59 and increase $5.9752 \%$ comparing with the value in 2014. The second one is the larger predictive value at 1444.88 , growing $6.8089 \%$ than that in 2014 . The third one is the large predictive value at 1524.09 which rises $12.6652 \%$ than that in 2014 . The last one is the small predictive value at 1410.62 , going up $4.2772 \%$ than that in 2014.

Tab. 3 Applying F2(3-4-4) prediction rules to forecastthe tourist number of Sanya in 2015

\begin{tabular}{|c|c|c|c|c|c|}
\hline years & Predicted types & $\begin{array}{l}\text { Predicted } \\
\text { value in } \\
2015 \\
\mathrm{~T}_{2015}(10 \mathrm{k})\end{array}$ & $\begin{array}{l}\text { Actual value } \\
\text { in } 2014 \\
\mathrm{U}_{2014}(10 \mathrm{k})\end{array}$ & $\left|T_{2015}-U_{2014}\right| / U_{2014}$ & $\begin{array}{l}\text { Recommen } \\
\text { d order }\end{array}$ \\
\hline 2015 & Small & 1410.62 & 1352.76 & $4.2772 \%$ & 4 \\
\hline 2015 & predictive & 1433.59 & 1352.76 & $5.9752 \%$ & 1 \\
\hline 2015 & value & 1444.88 & 1352.76 & $6.8089 \%$ & 2 \\
\hline 2015 & $\begin{array}{l}\text { Smaller } \\
\text { predictive } \\
\text { value } \\
\text { Larger } \\
\text { predictive } \\
\text { value } \\
\text { Large } \\
\text { predictive } \\
\text { value }\end{array}$ & 1524.09 & 1352.76 & $12.6652 \%$ & 3 \\
\hline
\end{tabular}

As for the second method, the decision-makers need to choose the order on the basis of their own experience.

\section{Conclusion}

FTSFM 2 is a collection of fuzzy time-series forecasting model and F2 (0.004) is one of the commonly used forecasting models. F2 (0.004) has historical data for predicting function, but also has forecasting of unknown years capability.

It provides a recommend order for all the predictive value of the unknown year, at the same time, it presents another method which makes the decision-makers do the choice based on their own experience. F2 (0.004) provides a new forecasting model for the study of tourism economic forecasting problems and also the general time series forecasting problems. 


\section{Acknowledgements}

This research was financially supported by Hainan Province Higher Education Institution Reform Funds, China (Grant NO. HNJG2015ZD-13), Hainan Province project for research development demonstration and promotion of applied technology (Grant NO. ZDXM2015134), Hainan Province Higher Education Institution Research Funds, China (Grant NO. HNJGZD2014-10).

\section{References}

1. L A Zadeh. Fuzzy set [J].Fuzzy Sets and Systems, 1965, 8: 338-353.

2. Q Song, B S Chissom. Forecasting enrollments with fuzzy time series [J].Fuzzy Sets and Systems, 1993, 54: 269-277.

3. Q Song, B S Chissom. Forecasting enrollments with fuzzy time series-Part I[J].Fuzzy Sets and Systems, 1993, 54: 1-9.

4. Q Song, B S Chissom. Forecasting enrollments with fuzzy time series-Part II[J].Fuzzy Sets and Systems, 1994, 62: 1-8.

5. Preetika Saxena, Kalyani Sharma, Santhosh Easo. Forecasting enrollments based on fuzzy time series with higher forecast accuracy rate [J]. Int. J. Computer Technology\& Applications, Vol.3, No.3, pp: 957-961, 2012.

6. H X Wang, J C Guo, H Feng, F J Zhang. A new model of forecast enrollment using fuzzy time series. Education Management and Management Science, 2014 International Conference on Education Management and Management Science (ICEMMS 2014), 7-8 August,2014,Tianjin, China, pp: 95-98.

7. HongXu Wang, JianChun Guo, Hao Feng, HaiLong Jin. A fuzzy time series forecasting model based on percentages. 2nd International Conference on Frontiers in Computer Education (ICFCE2014), December 24-25, 2014, Wuhan, China. 1 ICT IN EDUCATION. Frontiers in Computer Education. pp: 11-14, 2014, 2014.

8. Hongxu Wang, Jianchun Guo, Hao Feng, and Hailong Jin. A new forecasting model of fuzzy time series. Applied Mechanice and Materials, 2014, Vol .678: 59-63.

9. HongXu Wang, JianChun Guo, Hao Feng, HaiLong Jin. A fuzzy time series forecasting model based on data differences. 2nd International Conference on Frontiers in Computer Education (ICFCE2014), December 24-25, 2014, Wuhan, China. 1 ICT IN EDUCATION. Frontiers in Computer Education. pp: 15-18, 2014. 
10. Hongxu Wang, Jianchun Guo, Hao Feng, and Hailong Jin. An improved forecasting model of fuzzy time series. Applied Mechanice and Materials, Vol .678: 64-69, 2014. 